Pacific Journal of Mathematics

ABSOLUTE CONVERGENCE FIELDS OF SOME TRIANGULAR 


\title{
ABSOLUTE CONVERGENCE FIELDS OF SOME TRIANGULAR MATRIX METHODS
}

\author{
ARUn Kumar aND D. P. SAHU
}

Recently Das [2] has obtained results on the comparison of the absolute convergence fields between the Nörlund matrix and its product with the Cesàro matrix. In the present paper a similar investigation for the Riesz matrix $\left(\left(\bar{N}, p_{n}\right)\right.$ matrix $)$ is made.

1. Let $A=\left(a_{n, k}\right)$ be an infinite lower triangular matrix, that is $a_{n, k}=0$, if $k>n$, transforming sequence $s \equiv\left\{s_{n}\right\}$ into the sequence $A(s)$ defined by

$$
A(s)=\left\{A_{n}(s)\right\}=\left\{\sum_{k=0}^{n} a_{n, k} s_{k}\right\} .
$$

The sequence $s$ is said to be absolutely summable $A$ or summable $|A|$, if the transformed sequence $A(s)$ is of bounded variation, that is if $\sum_{n=1}^{\infty}\left|A_{n}(s)-A_{n-1}(s)\right|<\infty$. The absolute convergence field of $A$, denoted by $|A|$, is the set of all sequences which are summable $|A|$. The matrix $A$ is said to be absolute conservative if $|I| \subseteq|A|$, where $I$ is the identity matrix.

Let $\left\{p_{n}\right\}$ be a sequence of constants, real or complex, such that $P_{n}=\sum_{k=0}^{n} p_{k} \neq 0$. When $a_{n, k}=\left(p_{n-k}\right) / P_{n}, A$ is called the $\left(N, p_{n}\right)$ matrix and for $a_{n, k}=p_{k} / P_{n}, A$ is called the $\left(\bar{N}, p_{n}\right)$ matrix. The $\left(\bar{N}, p_{n}\right)$ matrix for $p_{n}>0$ and $P_{n} \rightarrow \infty$ is also denoted by the $\left(R, P_{n}, 1\right)$ matrix. When the sequence $\left\{p_{n}\right\}$ is such that $p_{n}=1$ for all $n$, both the $\left(N, p_{n}\right)$ and the $\left(\bar{N}, p_{n}\right)$ matrices reduce to the $(C, 1)$ matrix.

For two matrix methods $A$ and $B, A B$ transform of $s$ is defined by $A(B(s))$. In particular,

$$
\bar{t}_{m}(p, q)=\frac{1}{P_{m}} \sum_{k=0}^{m} \frac{p_{k}}{Q_{k}} \sum_{n=0}^{k} q_{n} s_{n},
$$

where $\bar{t}_{n}(p, q)$ denotes $\left(\bar{N}, p_{n}\right)\left(\bar{N}, q_{n}\right)$ transform of $s$.

Throughout the present paper we write $P_{n}^{(1)}=\sum_{k=0}^{n} p_{k}$, and for any sequence $\left\{\theta_{n}\right\}, \Delta n \theta_{n}=\Delta \theta_{n}=\theta_{n}-\theta_{n+1}$ and $\theta_{n}=0$, if $n<0 ; K$ denotes a positive constant, not necessarily the same at each occurrence.

2. Concerning the relative inclusion of the absolute convergence fields of $\left(N, p_{n}\right)$ and $\left(N, p_{n}\right)(C, 1)$, the following is known (see Das [2], Theorem 2 and Theorem 5).

TheOREM A. Let the sequence $\left\{p_{n}\right\}$ be such that $p_{n}>0$ and 
$p_{n+1} / p_{n} \leqq p_{n+2} / p_{n+1} \leqq 1 . \quad$ Then $\left|N, P_{n}\right| \subseteq\left|(C, 1)\left(N, p_{n}\right)\right|$

Silverman [5] has shown that the $\left(N, p_{n}\right)$ matrix is not permutable with the $(C, 1)$ matrix unless the $\left(N, p_{n}\right)$ matrix is a Cesàro matrix. However, it has been proved that Theorem $\mathrm{A}$ is true even if the $(C, 1)\left(N, p_{n}\right)$ is permuted ([2], Theorem 4).

It has been proved (see Prasad and Pati (4)) that the absolute Riesz summability $\left|R, \lambda_{n}, r\right|$ implies the summability $\left|R, \phi\left(\lambda_{n}\right), r\right|$, provided, roughly speaking, the $\phi(x)$ is reasonable regular and does not increase more rapidly than a power of $x$. But from Lemma 4 we see that

$$
\left|\bar{N}, P_{n}\right| \subseteq\left|\bar{N}, p_{n}\right|
$$

if and only if $p_{n} P_{n}^{(1)}=O\left(\left(P_{n}\right)^{2}\right)$.

The following theorems which we prove in the present paper show that if we consider the product of $(C, 1)$ and $\left(\bar{N}, p_{n}\right)$ in place of $\left(\bar{N}, p_{n}\right)$ in (1.2) the relation (1.2) holds good for a fairly wider class of sequences $\left\{p_{n}\right\}$.

THEOREM 1. Let $\left\{p_{n}\right\}$ be a nonnegative sequence. Then $\left|\bar{N}, P_{n}\right| \subseteq$ $\left|(C, 1)\left(\bar{N}, p_{n}\right)\right|$, if

$$
\frac{k p_{k} P_{k}^{(1)}}{P_{k}} \sum_{n=k+1}^{\infty} \frac{1}{n^{2} P_{n}} \leqq K, \quad k=1,2, \cdots
$$

THEOREM 2. Let $\left\{p_{n}\right\}$ be a nonnegative sequence. Then

$$
\left|\bar{N}, P_{n}\right| \subseteq\left|\left(\bar{N}, p_{n}\right)(C, 1)\right|
$$

The condition (1.3) seems to be quite less restrictive but it is not true even for all nonnegative sequences; for if we consider the sequence $\left\{p_{n}\right\}$ such that $P_{0}=\log 2$ and for $n>0, p_{n}$ is chosen to be either 0 or 1 in such a way that $\log (n+2) \sim P_{n}$. It is easy to see that for this case (1.3) is not satisfied.

Concerning the inclusion relation between the absolute convergence fields of the $\left(\bar{N}, q_{n}\right)$ and the $(C, 1)\left(N, p_{n}\right)$ methods we prove the following.

THEOREM 3. Suppose that $\left\{p_{n}\right\}$ is nonnegative nonincreasing sequence and that $\left\{q_{n}\right\}$ is positive and nondecreasing sequence. Then

$$
\left|\bar{N}, q_{n}\right| \subseteq\left|(C, 1)\left(N, p_{n}\right)\right|
$$

It is interesting to observe that the relation $\left|\bar{N}, q_{n}\right| \subseteq$ $\left|\left(N, p_{n}\right)(C, 1)\right|$ also holds good follows from Lemma 4 . Since for non- 
decreasing sequence $\left\{q_{n}\right\}, Q_{n} \leqq(n+1) q_{n}$, we see that with $\left\{q_{n}\right\}$ in place of $\left\{p_{n}\right\}$ and $q_{n}=1$ in Lemma 4 , the hypotheses of Lemma 4 are satisfied. Hence

$$
\left|\bar{N}, q_{n}\right| \subseteq|C, 1|
$$

But for nonnegative nonincreasing sequence $\left\{p_{n}\right\}$ it follows from Lemma 3 that $\left(N, p_{n}\right)$ is absolutely regular. Hence $\left|\bar{N}, q_{n}\right| \subseteq$ $\left|\left(N, p_{n}\right)(C, 1)\right|$.

2. For the proof of the theorems we need the following results. In what follows we write $\alpha_{n}=p_{n+1} P_{n}^{(1)} / P_{n+1}$ and $C_{m}=m+1-$ $P_{m}^{(1)} / P_{m+1}$.

LEMma 1. In order that any $\left\{x_{n}\right\} \in|I|$ implies $\left\{x_{n}\right\} \in|A|$, where $A=\left(a_{m, n}\right)$, it is necessary and sufficient that $\sum_{k=0}^{\infty} a_{n, k}$ converges for all $n$ and

$$
\sum_{n=0}^{\infty}\left|\sum_{k=0}^{m}\left(a_{n+1, k}-a_{n, k}\right)\right| \leqq K, \quad m=0,1,2, \cdots .
$$

Lemma 1 is contained in ([6], Theorem 3).

Lemma 2. For $m, n=0,1,2, \cdots$

$$
\begin{gathered}
\sum_{k=0}^{m}\left(\Delta \frac{p_{k}}{P_{k}}\right) P_{k}^{(1)}=P_{m}-\alpha_{m} ; \\
\sum_{k=0}^{m}\left(\Delta_{k} \frac{p_{n-k}}{q_{k}}\right) Q_{k}=P_{n}-P_{n-m-1}-\frac{p_{n-m-1} Q_{m}}{q_{m+1}} .
\end{gathered}
$$

The proof of Lemma 2 is direct. The following lemma is contained in [3].

LEMMA 3. If $\left\{p_{n}\right\}$ is nonegative, nonincreasing, then for all $k \geqq 0$ and $1 \leqq a \leqq b \leqq \infty$,

$$
\sum_{n=a}^{b} P(n, k)=\sum_{n=a}^{b}\left(\frac{P_{n-k}}{P_{n}}-\frac{P_{n-k-1}}{P_{n-1}}\right) \leqq 1,
$$

and, for any $n>0, P(n, k) \geqq 0$.

Lemma 4 . Let $q_{n}>0$ and $p_{n} \neq 0$. Then in order that $\left|\bar{N}, p_{n}\right| \subseteq$ $\left|\bar{N}, q_{n}\right|$, it is necessary and sufficient that $P_{n} / p_{n}=O\left(Q_{n} / q_{n}\right)$.

The sufficiency part of the lemma in a less general form is due to Sunouchi [6]. The present form is due to Bosanquet ([1], p. 654). 
3. Proof of Theorem 1. Let $\bar{t}_{n}(P)$ denote the $\left(\bar{N}, P_{n}\right)$ transform of $\left\{s_{n}\right\}$. We have

$$
P_{n} s_{n}=P_{n}^{(1)} \bar{t}_{n}(P)-P_{n-1}^{(1)} \bar{t}_{n-1}(P), \quad n=0,1,2, \cdots,
$$

so that

$$
\begin{aligned}
\bar{t}_{n}(1, p) & =\frac{1}{n+1} \sum_{s=0}^{n} \frac{1}{P_{s}} \sum_{r=0}^{s} \frac{p_{r}}{P_{r}}\left(P_{r}^{(1)} \bar{t}_{r}(P)-P_{r-1}^{(1)} \bar{t}_{r-1}(P)\right) \\
& =\frac{1}{n+1} \sum_{s=0}^{n} \frac{1}{P_{s}}\left\{\sum_{r=0}^{s}\left(\Delta \frac{p_{r}}{P_{r}}\right) P_{r}^{(1)} \bar{t}_{r}(P)+\alpha_{s} \bar{t}_{s}(P)\right\} \\
& =\frac{1}{n+1} \sum_{r=0}^{n}\left\{\sum_{s=r}^{n}\left(\Delta \frac{p_{r}}{P_{r}}\right) \frac{P_{r}^{(1)}}{P_{s}}+\frac{\alpha_{r}}{P_{r}}\right\} \bar{t}_{r}(P) \\
& =\sum_{r=0}^{n} a_{n, r} \bar{t}_{r}(P),
\end{aligned}
$$

say. Writing $\beta_{n, m}=\sum_{r=0}^{m} a_{n, r}$ and observing that $a_{n, r}=0$ for $r>n$ we see that $\beta_{n, m}=1$ for $n \leqq m$ and for $n \geqq m$

$$
\beta_{n, m}=\frac{1}{n+1} \sum_{r=0}^{m}\left\{\sum_{s=r}^{n}\left(\Delta \frac{p_{r}}{P_{r}}\right) \frac{P_{r}^{(1)}}{P_{s}}+\frac{\alpha_{r}}{P_{r}}\right\} .
$$

We first simplify $\beta_{n, m}$ for $n \geqq m$. By virtue of the result (i) of Lemma 2, we have ${ }^{1}$

$$
\begin{aligned}
\sum_{r=0}^{m} \sum_{s=r}^{n} & \left(\Delta \frac{p_{r}}{P_{r}}\right) \frac{P_{r}^{(1)}}{P_{s}} \\
& =\sum_{r=0}^{m}\left(\sum_{s=r}^{m}+\sum_{s=m+1}^{n}\right)\left(\Delta \frac{p_{r}}{P_{r}}\right) \frac{P_{r}^{(1)}}{P_{s}} \\
& =\sum_{s=0}^{m} \frac{1}{P_{s}} \sum_{r=0}^{s} P_{r}^{(1)}\left(\Delta \frac{p_{r}}{P_{r}}\right)+\sum_{s=m+1}^{n} \frac{1}{P_{s}} \sum_{r=0}^{m} P_{r}^{(1)}\left(\Delta \frac{p_{r}}{P_{r}}\right) \\
& =m+1+\left(P_{m}-\alpha_{m}\right) \sum_{s=m+1}^{n} 1 / P_{s}-\sum_{s=0}^{m} \alpha_{s} / P_{s}
\end{aligned}
$$

so that

$$
\beta_{n, m}=\frac{m+1}{n+1}+\frac{1}{n+1}\left(P_{m}-\alpha_{m}\right) \sum_{s=m+1}^{n} \frac{1}{P_{s}} .
$$

In order to prove the theorem, it is sufficient to show that the matrix $\left(a_{n, r}\right)$ in (3.1) is absolutely conservative. From Lemma 1, we see that the matrix $\left(a_{n, r}\right)$ will be absolutely conservative if

$$
\sum \equiv \sum_{n=m}^{\infty}\left|\beta_{n+1, m}-\beta_{n, m}\right| \leqq K, \quad m=0,1,2, \cdots,
$$

since $\beta_{n, m}=1$ for $n \leqq m$. From (3.2) we get

1 We assume here onwards $\sum_{a}^{b}=0$ if $b<a$. 


$$
\begin{aligned}
\sum=\sum_{n=m}^{\infty} \mid \frac{m+1}{(n+1)(n+2)} & +\frac{1}{(n+1)(n+2)}\left(P_{m}-\alpha_{m}\right) \sum_{s=m+1}^{n} \frac{1}{P_{s}} \\
& -\frac{1}{(n+2) P_{n+1}}\left(P_{m}-\alpha_{m}\right) \mid .
\end{aligned}
$$

Evidently,

$$
\sum \leqq \sum_{n=m}^{\infty}(m+1) /(n+1)(n+2)+R(m)+L(m),
$$

where

$$
R(m)=P_{m} \sum_{n=m}^{\infty}\left|\frac{1}{(n+1)(n+2)} \sum_{s=m+1}^{n} \frac{1}{P_{s}}-\frac{1}{(n+2) P_{n+1}}\right|
$$

and $L(m)=\alpha_{m} R(m) / P_{m}$.

We have

$$
\begin{aligned}
R(m) \leqq & P_{m} \sum_{n=m}^{\infty} \frac{1}{(n+1)(n+2)}\left|\sum_{s=m+1}^{n} \frac{1}{P_{s}}-\frac{n-m}{P_{n+1}}\right| \\
& \quad+P_{m} \sum_{n=m}^{\infty} \frac{m+1}{(n+1)(n+2) P_{n+1}} \\
= & P_{m} X(m)+P_{m} Y(m), \text { say . }
\end{aligned}
$$

In view of the fact that for nonnegative sequence $\left\{p_{n}\right\},\left\{P_{n}\right\}$ is nondecreasing, it follows that

$$
P_{m} Y(m) \leqq K \text {. }
$$

Observing that $\sum_{s=m}^{n} 1 / P_{s}>(n-m) / P_{n}$, we obtain

$$
X(m)=\sum_{n=m}^{\infty}\left\{\frac{1}{(n+1)(n+2)} \sum_{s=m+1}^{n} \frac{1}{P_{s}}-\frac{1}{(n+2) P_{n+1}}\right\}+Y(m) .
$$

We now prove that $P_{m} X(m) \leqq K$. For, we first estimate

$$
X^{*}(N, m)=\sum_{n=m}^{N}\left\{\frac{1}{(n+1)(n+2)} \sum_{s=m+1}^{n} \frac{1}{P_{s}}-\frac{1}{(n+2) P_{n+1}}\right\} .
$$

First changing the order of summation and then using that $\sum_{n=s}^{N} 1(n+1) n=1 / s-1 /(N+1)$, we get

(3.6) $X^{*}(N, m)=\sum_{s=m+1}^{N} \frac{1}{(s+1) P_{s}}-\frac{1}{N+2} \sum_{s=m+1}^{N} \frac{1}{P_{s}}-\sum_{n=m+1}^{N+1} \frac{1}{(n+1) P_{n}}$.

If $P_{n} \rightarrow \infty$ as $n \rightarrow \infty$, it follows from (3.6) that $X^{*}(N, m) \rightarrow 0$ as $N \rightarrow \infty$. If $P_{n} \nrightarrow \infty$, then, since $\left\{P_{n}\right\}$ is nondecreasing, $P_{n} \rightarrow a$ finite limit $P$, say, as $n \rightarrow \infty$; and in this case $X^{*}(N, m) \rightarrow-1 / P$. In view of this and (3.5) it follows that

$$
P_{m} X(m) \leqq K .
$$


From (3.5) and (3.7) we get

$$
R(m) \leqq K .
$$

Now we estimate $L(m)$. We have

$$
L(m) \leqq \alpha_{m}(X(m)+Y(m)) .
$$

From the hypothesis (1.3) we see that $\alpha_{n}$ is bounded whenever $P_{n} \leqq K$. Using this fact and the observations made just after (3.5), we see that $\alpha_{m} X(m) \leqq K$. That $\alpha_{m} y(m) \leqq K$ follows from the hypothesis (1.3). Thus $L(m) \leqq K$. This together with (3.8) and (3.4) yields $\Sigma=O(1)$, since the first term in (3.4) is bounded. This proves Theorem 1.

Proof of Theorem 2. Following closely the proof for (3.1) we see that

$$
\begin{aligned}
\bar{t}_{n}(p, 1) & =\frac{1}{P_{n}} \sum_{r=0}^{n}\left\{\sum_{s=r}^{n} \frac{p_{s} P_{r}^{(1)}}{s+1}\left(\Delta \frac{1}{P_{r}}\right)+\frac{p_{r} P_{r}^{(1)}}{(r+1) P_{r+1}}\right\} \bar{t}_{r}(P) \\
& =\sum_{r=0}^{n} a_{n, r} \bar{t}_{r}(P) .
\end{aligned}
$$

Thus, in this case

$$
\beta_{n, m}=\frac{1}{P_{n}} \sum_{r=0}^{m}\left\{\sum_{s=r}^{n} \frac{p_{s} P_{r}^{(1)}}{s+1}\left(\Delta \frac{1}{P_{r}}\right)+\frac{p_{r} P_{r}^{(1)}}{(r+1) P_{r+1}}\right\}
$$

for $n \geqq m$ and $\beta_{n, m}=1$ for $m \geqq n$.

Using the technique, with the result (ii) in place of (1) of Lemma 2 , for obtaining (3.2) we see that

$$
\beta_{n, m}=P_{m} / P_{n}+\left(C_{m} / P_{n}\right) \sum_{s=m+1}^{n} p_{s} /(s+1) .
$$

Now we proceed to prove that for this case also (3.3) holds good. We have

$$
\begin{aligned}
\Sigma \equiv & \sum_{n=m}^{\infty}\left|\frac{p_{n+1} P_{m}}{P_{n} P_{n+1}}+C_{m} \frac{p_{n+1}}{P_{n+1}}\left(\frac{1}{P_{n}} \sum_{s=m+1}^{n} \frac{p_{s}}{s+1}-\frac{1}{n+2}\right)\right| \\
\leqq & \mathrm{C}_{m} \sum_{n=m}^{\infty} \frac{p_{n+1}}{P_{n+1}}\left|\frac{1}{P_{n}} \sum_{s=m+1}^{n} \frac{p_{s}}{s+1}-\frac{P_{n}-P_{m}}{(n+2) P_{n}}\right| \\
& +C_{m} P_{m} \sum_{n=m}^{\infty} \frac{p_{n+1}}{(n+2) P_{n} P_{n+1}}+P_{m} \sum_{n=m+1}^{\infty} \frac{p_{n+1}}{P_{n} P_{n+1}} \\
= & \Sigma_{1}+\Sigma_{2}+\Sigma_{3} .
\end{aligned}
$$

To prove that $\Sigma_{1}$ is bounded we first consider the following sum

$$
\Sigma(N)=\sum_{n=m+1}^{N} \frac{p_{n+1}}{P_{n+1}}\left|\frac{1}{P_{n}} \sum_{s=m+1}^{n} \frac{p_{s}}{s+1}-\frac{P_{n}-P_{m}}{(n+2) P_{n}}\right| .
$$


Observing that $(n+2) \sum_{s=m+1}^{n} p_{s} /(s+1)>P_{n}-P_{m}$ we see that the expression under the modulus sign in $\Sigma(N)$ is nonnegative. Hence by a change of order of summation we get

$$
\begin{aligned}
\Sigma(N)= & \sum_{s=m+1}^{N} \frac{p_{s}}{s+1} \sum_{n=s}^{N} \frac{p_{n+1}}{P_{n} P_{n+1}}-\sum_{n=m+1}^{N} \frac{p_{n+1}}{(n+2) P_{n+1}} \\
& +P_{m} \sum_{s=m+1}^{N} \frac{p_{n+1}}{(n+2) P_{n} P_{n+1}} .
\end{aligned}
$$

Since

$$
\sum_{n=s}^{N} p_{n+1} / P_{n} P_{n+1}=1 / P_{s}-1 / P_{N+1}
$$

and $p_{n} / P_{n} \leqq 1$, we have

$$
\begin{aligned}
\Sigma(N) & \leqq \frac{K}{m+1}+\frac{1}{P_{N+1}} \sum_{s=m}^{N} \frac{p_{s}}{s+1}+\frac{P_{m}}{m+3} \sum_{s=m+1}^{N} \frac{p_{n+1}}{P_{n} P_{n+1}} \\
& \leqq \frac{K}{m+1}+\frac{1}{(m+1) P_{N+1}} \sum_{s=0}^{N} p_{s} \leqq \frac{K}{m+1} .
\end{aligned}
$$

It is clear that the term of $\Sigma_{1}$ for $n=m$ is bounded. In view of this and (3.10) we get that $\Sigma_{1}$ is bounded, since $C_{m} \leqq K m$ by the fact that $P_{m}^{(1)} \leqq(m+1) P_{m}$. That $\Sigma_{2}$ and $\Sigma_{3}$ are bounded follows from (3.9). Thus we get that $\Sigma \leqq K$ for all $m$. This completes the proof of the theorem.

Proof of Theorem 3. It is interesting to observe from the result (1.4) that to prove Theorem 3, it is sufficient to show that $|C, 1| \subseteq\left|(C, 1)\left(N, p_{n}\right)\right|$, which is just special case of Theorem 3 when $\left(\bar{N}, q_{n}\right)$ is $(C, 1)$. But to prove this special case we require the same argument (except minor simplification of the method of the proof) as for the general case. In order to give a direct proof we consider the general case.

We have

Let $t_{n}(1, p)$ denote $(C, 1)\left(N, p_{n}\right)$ transform of the sequence $\left\{s_{n}\right\}$.

$$
t_{n}(1, p)=\frac{1}{n+1} \sum_{r=0}^{n}\left\{\sum_{k=r}^{n}\left(\Delta_{r} \frac{p_{k-r}}{q_{r}}\right) \frac{Q_{r}}{P_{k}}\right\} \bar{t}_{r}(q)=\sum_{r=0}^{n} a_{n, r} \bar{t}_{r}(q) .
$$

So far the case

$$
\beta_{n, m}=\frac{1}{n+1} \sum_{r=0}^{m} \sum_{k=r}^{n}\left(\Delta_{r} \frac{p_{k-r}}{q_{r}}\right) \frac{Q_{r}}{P_{k}} .
$$

It is clear that $\beta_{n, m}=1$ if $m \geqq n$. Simplifying by using Lemma 2(ii) we see that for $m \leqq n$ 


$$
\beta_{n, m}=1-\frac{1}{n+1} \sum_{k=m+1}^{n}\left(\frac{P_{k-m-1}}{P_{l}}+\frac{Q_{m} p_{k-m-1}}{q_{m+1} P_{k}}\right) .
$$

Now we prove that (3.3) is true for this case also. We have

$$
\begin{aligned}
\Sigma \equiv & \sum_{n=m}^{\infty} \mid \frac{1}{n+2}\left(\frac{1}{n+1} \sum_{k=m+1}^{n} \frac{P_{k-m-1}}{P_{k}}-\frac{P_{n-m}}{P_{n+1}}\right) \\
& -\frac{Q_{m}}{q_{m+1}}\left(\frac{p_{n-m}}{(n+2) P_{n+1}}-\frac{1}{(n+1)(n+2)} \sum_{k=m+1}^{n} \frac{p_{k-m-1}}{P_{k}}\right) \mid \\
\leqq & \lim _{M \rightarrow \infty} \sum_{n=m}^{M}\left|\frac{P_{n-m}}{(n+2) P_{n+1}}-\frac{1}{(n+2)(n+1)} \sum_{k=m+1}^{n} \frac{P_{k-m-1}}{P_{k}}\right| \\
& +\frac{Q_{m}}{q_{m+1}} \sum_{n=m}^{\infty} \frac{p_{n-m}}{(n+2) P_{n+1}}+\frac{Q_{m}}{q_{m+1}} \sum_{n=m}^{\infty} \frac{1}{(n+1)(n+2)} \sum_{k=m+1}^{n} \frac{p_{k-m-1}}{P_{k}} \\
= & \lim _{M \rightarrow \infty} \Sigma^{\prime}(M)+\Sigma^{\prime \prime}+\Sigma^{\prime \prime \prime},
\end{aligned}
$$

say. We first consider $\Sigma^{\prime}(M)$. Since for nondecreasing sequence $\left\{p_{n}\right\},\left\{P_{k-m-1} / P_{k}\right\}$ is nondecreasing in $k$ for $k>m$, we get that the expression under the modulus sign in $\Sigma^{\prime}(M)$ is nonnegative. By a change of order of summation we obtain

$$
\begin{aligned}
\Sigma^{\prime}(M) & =\sum_{n=m+1}^{M} \frac{P_{n-m}}{(n+2) P_{n+1}}-\sum_{k=m+1}^{M} \frac{P_{k-m-1}}{(k+1) P_{k}}+\frac{1}{M+2} \sum_{k=m+1}^{M} \frac{P_{k-m-1}}{P_{k}} \\
& \leqq \frac{P_{M-m}}{(M+2) P_{M+1}}-\frac{p_{0}}{(m+2) P_{m+1}}+\frac{1}{M+2} \sum_{k=m+1}^{M} 1 \leqq K .
\end{aligned}
$$

Hence

$$
\Sigma^{\prime}(M)=O(1) .
$$

To prove the boundedness of $\Sigma^{\prime \prime}$ and $\Sigma^{\prime \prime \prime}$ we first estimate the following sum. Observing that $(n-m+1) p_{n-m} \leqq P_{n-m} \leqq P_{n+1}$ we see that for $a=1$ or 2

$$
\begin{aligned}
& \sum_{n=m}^{\infty} \frac{p_{n-m}}{(n+a) P_{n+1}}=\sum_{n=m}^{2 m} \frac{p_{n-m}}{(n+a) P_{n+1}}+\sum_{n=2 m+1}^{\infty} \frac{p_{n-m}}{(n+a) P_{n+1}} \\
& \quad \leqq \frac{P_{m}}{(m+a) P_{m+1}}+\sum_{n=2 m+1}^{\infty} \frac{1}{(n-m)(n-m+1)} \leqq \frac{K}{m+1} .
\end{aligned}
$$

Since for nondecreasing sequence $\left\{q_{n}\right\}, Q_{n} \leqq(n+1) q_{n}$, we obtain from (3.13) that

$$
\Sigma^{\prime \prime}<\infty .
$$

Applying the above reasoning after a change of order of summation, we see that

$$
\Sigma^{\prime \prime \prime}=\frac{Q_{m}}{q_{m+1}} \sum_{k=m+1}^{\infty} \frac{p_{k-m-1}}{(k+1) P_{k}}<\infty .
$$


That $\Sigma$ is bounded follows when we use (3.12), (3.14) and (3.15) in (3.11). This completes the proof of Theorem 3 .

The authors would like to express their grateful thanks to Professor B. Kuttner of the University of Birmingham for some valuable comments. Our thanks are also due to Professor H. P. Dikshit and a referee for comments which have imporved presentation of the paper.

\section{REFERENCES}

1. L. S. Bosanquet, Mathematical Reviews, 11 (1950), 654.

2. G. Das, Tauberian theorems for absolute Nörlund summability, Proc. London Math. Soc., (3), 19 (1969), 357-384.

3. H. P. Dikshit and A. Kumar, Absolute summability of Fourier series with factors, Pacific J. Math., 61 (1975), 59-69.

4. B. N. Prasad and T. Pati, The second theorem of consistency in the the theory of absolute Riesz summability, Math. Annalen, 140 (1960), 187-197.

5. L. L. Silverman, Products of Nörlund transformations, Bull. Amer. Math. Soc., 43 (1937), 95-101.

6. G. Sunouchi, Notes on Fourier Analysis. (XVIII): Absolute summability of series with constant terms, Tôhoku Math. J. (2), 1 (1949), 57-65.

Received June 20, 1980 and in revised form October 9, 1980.

UNIVERSITY OF JABALPUR

JABALPUR (INDIA) 



\section{PACIFIC JOURNAL OF MATHEMATICS}

EDITORS

DONALD BABBITT (Managing Editor)

University of California

Los Angeles, CA 90024

Hugo RossI

University of Utah

Salt Lake City, UT 84112

C. C. MOORE and ANDREW OGG

University of California

Berkeley, CA 94720

\section{J. DugundjI}

Department of Mathematics

University of Southern California

Los Angeles, CA 90007

R. FINN and J. MILGRAM

Stanford University

Stanford, CA 94305

\section{ASSOCIATE EDITORS}
R. ARENS
E. F. BECKENBACH
B. H. NEUManN
F. WOLF
K. YoSHIDA

\section{SUPPORTING INSTITUTIONS}

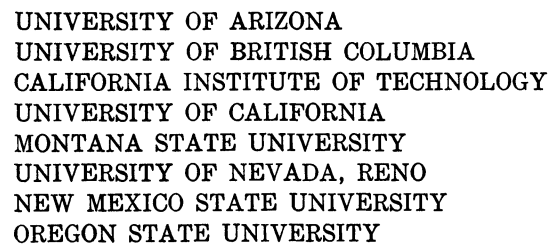

UNIVERSITY OF ARIZONA

UNIVERSITY OF BRITISH COLUMBIA

CALIFORNIA INSTITUTE OF TECHNOLOGY

UNIVERSITY OF CALIFORNIA

MONTANA STATE UNIVERSITY

UNIVERSITY OF NEVADA, RENO

NEW MEXICO STATE UNIVERSITY

OREGON STATE UNIVERSITY

\author{
UNIVERSITY OF OREGON \\ UNIVERSITY OF SOUTHERN CALIFORNIA \\ STANFORD UNIVERSITY \\ UNIVERSITY OF HAWAII \\ UNIVERSITY OF TOKYO \\ UNIVERSITY OF UTAH \\ WASHINGTON STATE UNIVERSITY \\ UNIVERSITY OF WASHINGTON
}

The Supporting Institutions listed above contribute to the cost of publication of this Journal, but they are not owners or publishers and have no responsibility for its content or policies.

Mathematical papers intended for publication in the Pacific Journal of Mathematics should be in typed form or offset-reproduced, (not dittoed), double spaced with large margins. Please do not use built up fractions in the text of the manuscript. However, you may use them in the displayed equations. Underline Greek letters in red, German in green, and script in blue. The first paragraph or two must be capable of being used separately as a synopsis of the entire paper. Please propose a heading for the odd numbered pages of less than 35 characters. Manuscripts, in triplicate, may be sent to any one of the editors. Please classify according to the scheme of Math. Reviews, Index to Vol. 39. Supply name and address of author to whom proofs should be sent. All other communications should be addressed to the managing editor, or Elaine Barth, University of California, Los Angeles, California, 90024.

50 reprints to each author are provided free for each article, only if page charges have been substantially paid. Additional copies may be obtained at cost in multiples of 50 .

The Pacific Journal of Mathematics is issued monthly as of January 1966. Regular subscription rate: $\$ 102.00$ a year (6 Vols., 12 issues). Special rate: $\$ 51.00$ a year to individual members of supporting institutions.

Subscriptions, orders for numbers issued in the last three calendar years, and changes of address shoud be sent to Pacific Journal of Mathematics, P.O. Box 969, Carmel Valley, CA 93924, U.S.A. Old back numbers obtainable from Kraus Periodicals Co., Route 100, Millwood, NY 10546.

\section{PUBLISHED BY PACIFIC JOURNAL OF MATHEMATICS, A NON-PROFIT CORPORATION}

Printed at Kokusai Bunken Insatsusha (International Academic Printing Co., Ltd.). 8-8, 3-chome, Takadanobaba, Shinjuku-ku, Tokyo 160, Japan. 


\section{Pacific Journal of Mathematics}

\section{Vol. 97, No. $2 \quad$ February, 1981}

Patrick Robert Ahern and N. V. Rao, A note on real orthogonal measures . . . . . 249

Kouhei Asano and Katsuyuki Yoshikawa, On polynomial invariants of fibered

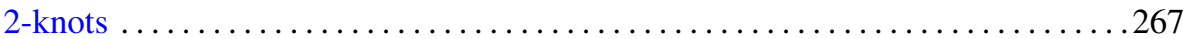

Charles A. Asmuth and Joe Repka, Tensor products for $S L_{2}(\mathscr{K})$. I.

Complementary series and the special representation

Gary Francis Birkenmeier, Baer rings and quasicontinuous rings have a

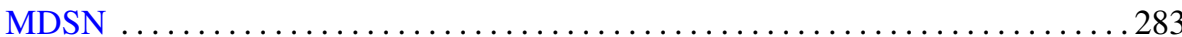

Hans-Heinrich Brungs and Günter Törner, Right chain rings and the generalized

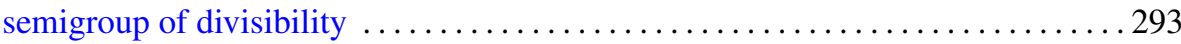

Jia-Arng Chao and Svante Janson, A note on $H^{1} q$-martingales . . . . . . . . . 307

Joseph Eugene Collison, An analogue of Kolmogorov's inequality for a class of

additive arithmetic functions

Frank Rimi DeMeyer, An action of the automorphism group of a commutative ring on its Brauer group

H. P. Dikshit and Anil Kumar, Determination of bounds similar to the Lebesgue

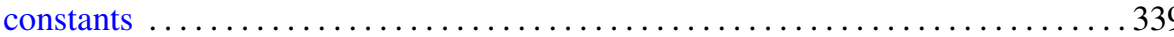

Eric Karel van Douwen, The number of subcontinua of the remainder of the plane

D. W. Dubois, Second note on Artin's solution of Hilbert's 17th problem. Order spaces

Daniel Evans Flath, A comparison of the automorphic representations of GL(3) and its twisted forms

Frederick Michael Goodman, Translation invariant closed $*$ derivations

Richard Grassl, Polynomials in denumerable indeterminates

K. F. Lai, Orders of finite algebraic groups

George Kempf, Torsion divisors on algebraic curves

Arun Kumar and D. P. Sahu, Absolute convergence fields of some triangular matrix methods

Elias Saab, On measurable projections in Banach spaces

Chao-Liang Shen, Automorphisms of dimension groups and the construction of AF algebras

Barry Simon, Pointwise domination of matrices and comparison of $\Phi_{p}$ norms

Chi-Lin Yen, A minimax inequality and its applications to variational inequalities

Stephen D. Cohen, Corrections to: "The Galois group of a polynomial with two indeterminate coefficients"

Phillip Schultz, Correction to: "The typeset and cotypeset of a rank 2 abelian group"

Pavel G. Todorov, Correction to: "New explicit formulas for the $n$th derivative of composite functions"

Douglas S. Bridges, Correction to: "On the isolation of zeroes of an analytic function" 